American Journal of Applied Sciences 7 (3): 366-370, 2010

ISSN 1546-9239

(C) 2010Science Publications

\title{
Sugar Beet Performance Affected by Uniformity of N Fertigation
}

\author{
${ }^{1}$ H. Nouri, ${ }^{1}$ M.S.M. Amin, ${ }^{2}$ S.J. Razavi, ${ }^{3}$ A.R. Anuar, ${ }^{4}$ W. Aimrun and ${ }^{5}$ S. Chavoshi Borujeni \\ ${ }^{1}$ Department of Biological and Agriculture Engineering, Faculty of Engineering, \\ University Putra Malaysia, Serdang 43400, Selangor, Malaysia \\ ${ }^{2}$ Department of Agricultural Machinery Engineering, \\ Isfahan University of Technology, Isfahan, 84156-83111, Iran \\ ${ }^{3}$ Department of Land Management, Faculty of Agriculture, \\ ${ }^{4}$ Smart Farming Technology Laboratory, Institute of Advanced Technology, \\ University Puta Malaysia, Serdang 43400, Selangor, Malaysia \\ ${ }^{5}$ Department of Environmental Science, Faculty of Environmental Studies, University Putra Malaysia, \\ Serdang 43400, Selangor, Malaysia Soil Conservation and Watershed Research Center of Iran, Malaysia
}

\begin{abstract}
In common with the majority of crop species, in sugar beet nutrition nitrogen is an important element due to its role in sucrose utilization and plant growth. Application of precision agriculture, in order to apply the right amount of input at the right time in the right area, is appropriate to decrease chemical use and increase plant growth. Problem statement: More often farmers apply fertilizers with low efficiency, low uniformity and high price such as spinner spreader, boom spreader or application with planting machines simultaneously. Fertigation can reduce labor cost and may improve uniformity, effectiveness and timeliness of application. Approach: The main objective of this study was to determine spatial variability of sugar beet performance affected by urea fertigation as well as established a management strategy based on spatial variability of tubers and soil total N. This study was conducted in Fesaran village, Isfahan Province of Iran and limited to sugar beet (monogerm seed). Urea applied through sprinklers. Soil samples were taken to determine soil total $\mathrm{N}$ as well as sugar beet tubers samples to specify yield. Results of soil and crop analysis were used to produce spatial variability maps through $\mathrm{GS}^{+}$and ArcGIS 9.2 software. Semivariogram results were used to perform an ordinary kriging to obtain interpolated values of selected variables from the sample points through and across the study area. Results: It was found that there was a low spatial variability of soil total $\mathrm{N}$ and yield which indicates that the soil has a homogenous total $\mathrm{N}$ as well as homogenous yield through and across the field. Yield variability map of sugar beet properties demonstrated that the higher yield was seen in the southern part of the study area where laterals were closer to pump. Conclusion: The results of urea fertigation through sprinklers showed pipeline layout and pump station position impact on variability of sugar beet properties.
\end{abstract}

Key words: Precision farming, spatial and temporal variability, sprinkler fertigation

\section{INTRODUCTION}

Distribution pattern of fertilizer application by fertigation is an important concern because of its influence on crop performance. Plant response is the common tool for farmers to decide about the adequacy of required nutrients but this may be too late to be useful. Spatial variability maps of soil and crop properties would be appropriate tools to make a precise management strategy. Solid set sprinkler or trickle systems provide sufficient distribution of water and $\mathrm{N}$ when appropriately designed and operated. These systems do not generally require constant $\mathrm{N}$ rate injection so some granular sources may be dissolved in water and batch loaded with a venturi injector or a mixing tank (Wright et al., 2002). Gardenas et al. (2005) asserted that the regular application of $\mathrm{N}$ fertigation can increase the nitrate concentrations in groundwater. Li et al. (2005) claimed that for sprinkler fertigation, one of the factors that can affect on nitrate leaching is irrigation uniformity. The effects of non uniformity fertigation on leaching of nitrate should be

Corresponding Author: H. Nouri, Department of Biological and Agriculture Engineering, Faculty of Engineering, University Putra Malaysia, Serdang 43400, Selangor, Malaysia 
considered in determining the target uniformity of sprinkler system design. The higher uniformity can decrease nitrate leaching but possibly will limit the use of sprinkler systems because the initial costs of these systems increase with increasing application uniformity. Varlev (1976) and Seginer (1983) expressed the interaction effects of irrigation amount and irrigation uniformity on crop properties. Mantovani et al. (1995) simulated crop yield which was affected by sprinkler irrigation whereas there is uniformity in sprinkler water distribution and linear function in crop water production. Li (1998) programmed a model to simulate yield relationship and evapotranspiration deficits at special growth stages to evaluate the impacts of sprinkler uniformity on crop yield. Models showed crop yield enhancement regarding to sprinkler uniformity, despite the result of an experimental research which was conducted by Mateos et al. (1997) and Li and Rao (2000). This study asserted that sprinkler uniformity has minor effect on crop yield. Pang et al. (1997) studied the effects of irrigation amount, uniformity and $\mathrm{N}$ amount and timing of split nitrogen application on crop yield and nitrate leaching. The result showed Christiansen Uniformity coefficient (CU) reduction from $100-75 \%$ increased nitrate leaching and yield reduction significantly. Allaire-Leung et al. (2001) deliberated role of nitrate leaching and soil nitrate content distribution on irrigation uniformity in a carrot field and concluded that irrigation depth and uniformity had slight impact on spatial distribution and nitrate leaching while uniformity was larger than $80 \%$. The research on the effect of fertigation distribution pattern and layout of sprinkler irrigation system (solid set with removable sprinklers) on the variability of sugar beet performance is a technique to explain the crop response to sprinkler fertigation. Therefore this study was to determine spatial variability of sugar beet performance affected by urea fertigation and establish a management strategy based on spatial variability of tubers quality and soil total $\mathrm{N}$.

\section{MATERIALS AND METHODS}

Soil and crop sampling was performed in a sugar beet field of 3.1 ha, located at Fesaran village, Esfahan in central part of Iran. Soil type was clay loam and loam. Water source for irrigation system was mixture of open channel which was feeding from Zayandeh-Rood river and deep well in the farm. Sugar beet (Beta vulgaris) was planted with the spacing of $20 \times 50 \mathrm{~cm}$ on 9th July 2007. Sugar beet field was fertigated by sprinkler irrigation system (solid set with removable sprinklers) applied Urea $(46 \% \mathrm{~N})$ with the rate of $200 \mathrm{~kg} \mathrm{ha}^{-1}$ (recommended rate by sugar factory researchers who observed this field for several years) on 30th August 2007. Geostatistical sampling was applied. A total of 10 laterals of sprinkler irrigation system cover 27 plots, typical plot size is $23 \times 23 \mathrm{~m}$ whereas sprinklers mounted on the $120 \mathrm{~cm}$ height and risers were installed at the corners of each plot. Three different points were recorded by Differential Global Positioning System (DGPS) and flagged for the different stages of soil and crop sampling. Soil samples were collected in 81 point at $30 \mathrm{~cm}$ depth (effective root zone for sugar beet). Soil samples were air dried, grinded and then sieved through $2 \mathrm{~mm}$ sieve. Soil status was studied in total $\mathrm{N}$ before fertigation on 4th July 2007 and after fertigation on 3th September 2007 to create spatial and temporal variability maps. Tuber samples were harvested on 4th December 2007. Full circle sprinklers namely AMBO (Italy) sprinkled $2.08 \mathrm{~L} \mathrm{sec}^{-1}$ of water at 4 bar pressure by $10 \mathrm{~mm}$ nozzle with $21 \mathrm{~m}$ effective wetted radius. A plot of $46 \times 46 \mathrm{~m}$ observed area was divided in grids of $3 \times 3 \mathrm{~m}$ subplot to apply catch can test. To measure water distribution pattern below the canopy, 240 catch cans of $250 \mathrm{~mm}$ height and $120 \mathrm{~mm}$ diameter were placed at the corner of each subplot on the ground surface and collected water for $1 \mathrm{~h}$.

The commonly used measurement tool to determine the uniformity of sprinkler systems is catch can test. Once the data are collected by catch cans, a number of different calculations can be performed. A common measurement of variability in water application includes coefficient of uniformity proposed by Christiansen (1941) and distribution uniformity:

$$
\mathrm{CU}=\left(1-\frac{\sum_{\mathrm{i}=1}^{\mathrm{n}}\left|\mathrm{x}_{\mathrm{i}}-\overline{\mathrm{x}}\right|}{\mathrm{N}_{\overline{\mathrm{x}}}}\right) \times 100
$$

Where:

$\mathrm{CU}=$ Christiansen uniformity coefficient

$\mathrm{x}_{\mathrm{i}} \quad=$ Water application depth

$\sum_{i=1}^{n}\left|x_{i}-\bar{x}\right|=$ Sum of the absolute deviation from the

$\mathrm{N}_{\overline{\mathrm{x}}} \quad=\quad \begin{aligned} & \text { mean } \mathrm{x} \text { of all } \mathrm{N} \text { observation } \\ & \text { Number of observations }\end{aligned}$

The distributional function was used to evaluate the Distribution Uniformity (DU) (Merriam and Keller, 1978):

$$
\mathrm{DU}=\frac{\text { Average low quarter depth }}{\text { Overall average depth }} \times 100 \%
$$


To produce variability maps of soil characteristics and crop properties, kriging method (Krige, 1984; Buyong, 2007) was used. In brief, the kriging is an advanced interpolation procedure generating estimated surfaces via semivariograms, which represent and characterize the spatial variation set against the distance (lag) (Isasks and Srivastava, 1989).

The spatial structure of each variable has been defined from semivariogram components which calculated by geostatistical analysis software through $\mathrm{GS}^{+}$(Geostatistics for the Environmental Sciences, Gamma Design Software, LLC Plainwell, Michigan). Ordinary kriging have been applied to extrapolate the values of unsampled field parts. To build kriged surface maps ArcGIS 9.2 was used (Blackmore, 1999; Aimrun et al., 2007). Thylen and Murphy

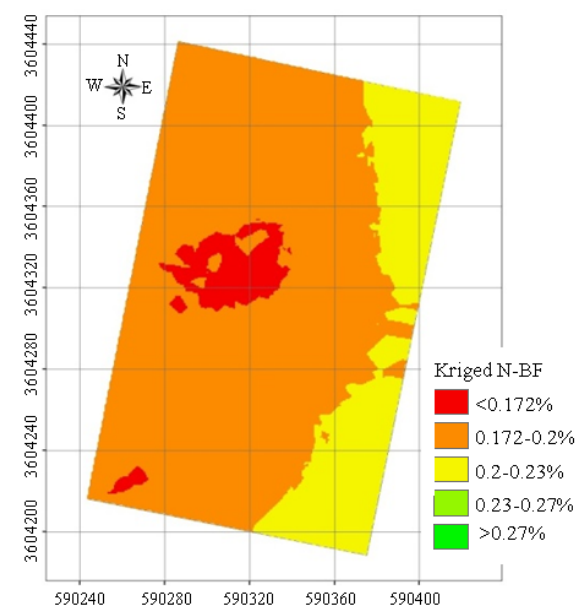

(a)
(1996); Blackmore and Marshall (1996) and Blackmore (1999) applied this technique in crop properties mapping.

\section{RESULTS}

Application uniformity as a major parameter of sprinkler irrigation efficiency was analyzed using quantitative measures of uniformity (Merkley and Allen, 2004). The distribution of sprinkler irrigation was determined by calculation of $\mathrm{CU}$ and DU which are $80.32 \%$ and $69.57 \%$. According to Merkley and Allen (2004), DU>65\% and CU>75\% are acceptable performance level for economic design. Also they claimed that CU $>70 \%$ conform a normal distribution of sprinkler irrigation system.

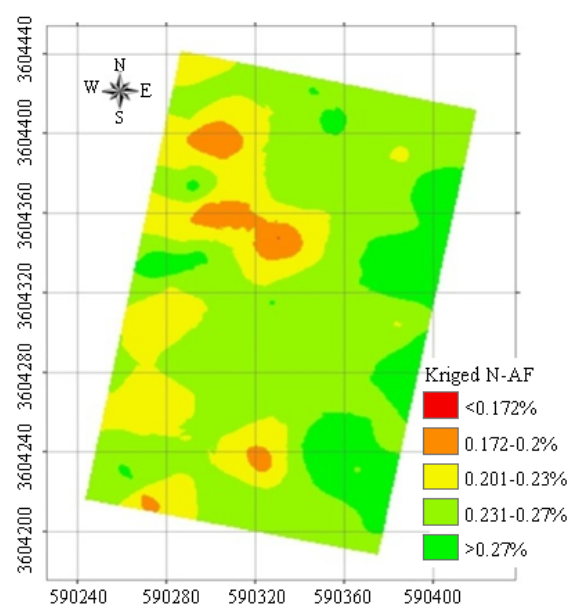

(b)

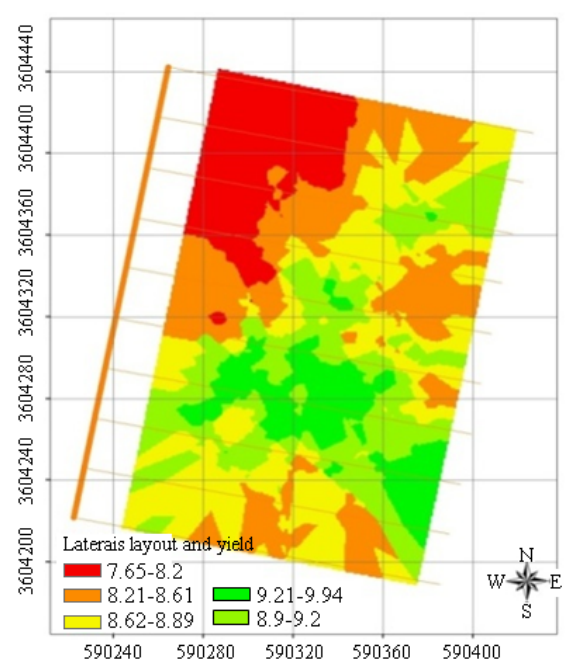

(c)

Fig. 1: Spatial Variability Maps (a) N-before fertigation, (b) N-after fertigation, (c) yield 
Am. J. Applied Sci., 7 (3): 366-370, 2010

Table 1: Geostatistical description of soil and crop properties

\begin{tabular}{llllllll}
\hline ID & Model type & Nugget & Sill & Range & Partial Sill & C/(C0+C) & RSS \\
\hline $\mathrm{N}(\%)-\mathrm{BF}$ & Spherical & 0.0003 & 0.0006 & 141.8 & 0.0003 & 0.510 & $5.36 \times 10^{-9}$ \\
$\mathrm{~N}(\%)-\mathrm{AF}$ & Spherical & $9.4 \times 10^{-5}$ & 0.0014 & 38.9 & 0.0013 & 0.930 & $2.1 \times 10^{-7}$ \\
Yield $\left(\mathrm{kg} \mathrm{m}^{-2}\right)$ & Spherical & 0.153 & 2.2560 & 21.1 & 2.1030 & 0.932 & 0.146 \\
\hline
\end{tabular}

Geostatistical analysis showed that spherical model is the best fitted model for soil total $\mathrm{N}$ before and after fertigation as well as sugar beet yield with the range of $141.8 \mathrm{~m}, 38.9$ and 21.1 range of variability, respectively (Table 1).

Smart Quantile was applied to classify whole study area in 5 zones to reveal the variability of soil and plant properties. To visualize the variability of 5 zones, they were defined as very low(red), low (orange), moderate (yellow), high (light green) and very high(dark green) application (Fig. 1). Pairwise-two tail test (t-test) confirmed higher mean $\mathrm{N}$ after fertigation than before fertigation.

\section{DISCUSSION}

It is apparent from Fig. 1a before fertigation soil total $\mathrm{N}$ varied from very low to medium rate while after fertigation it rose from medium to very high (Fig. 1b) which is related to urea application. Low amount of CV (less than 15\%) confirmed low variability of $\mathrm{N}$ through and across the study area. As can be seen in Fig. 1c higher yield (9.1-9.94 $\mathrm{kg} \mathrm{m}^{-2}$ ) was obtained from the southern part compared to lower yield (7.65-8.36 $\mathrm{kg} \mathrm{m}^{-2}$ ) from the northern part of the study area. The results of urea fertigation through sprinklers show pipeline layout and pump station position impact on variability of yield. Higher yield was seen in southern part of the study area where laterals are closer to pump station. S$\mathrm{N}-\mathrm{K}$ test (SAS) showed the homogeneity of 5 zones of soil total $\mathrm{N}$ and yield with no significant differences between means of different zones. It can be concluded that proper uniform distribution of sprinkler fertigation made uniform yield.

\section{CONCLUSION}

Results showed the effect of sprinkler irrigation system layout and sprinkler irrigation uniformity on spatial variability of sugar beet performance. Spatial variability of soil total $\mathrm{N}$ was influenced by uniformity of sprinkler fertigation. Low variability of soil total $\mathrm{N}$ and yield confirmed the acceptable uniformity of yield but precision fertigation by variable rate application equipment such as variable rate sprinklers would be more effective.

\section{ACKNOWLEDGMENT}

The researchers are grateful of support by Institute of Advanced Technology (ITMA) and Faculty of Engineering, University Putra Malaysia, Selangor, Malaysia and Department of Agricultural Machinery Engineering, Isfahan University of Technology, Isfahan, 84156-83111, Iran.

\section{REFERENCES}

Aimrun, W., M.S.M. Amin, D. Ahmad, M.M. Hanafi and C.S. Chan, 2007. Spatial variability of bulk soil electrical conductivity in a Malaysian paddy field: Key to soil management. Paddy Water Environ., 5: 113-121. DOI: 10.1007/s10333-007-0072-z

Allaire-Leung, S.E., L. Wu, J.P. Mitchell and B.L. Sanden, 2001. Nitrate leaching and soil nitrate content as affected by irrigation uniformity in a carrot field. Agric. Water Manage, 48: 37-50. DOI: 10.1016/S0378-3774(00)00112-8

Blackmore, B.S. and C.J. Marshall, 1996. Yield mapping; errors and algorithms. Proceeding of the 3rd International Conference on Precision Agriculture, June 23-26, Minneapolis, USA., pp: 403-405.

Blackmore, S., 1999. Remedial correction of yield map data. Precis. Agric., 1: 53-66. DOI: 10.1023/A:1009969601387

Buyong, T., 2007. Spatial Data Analysis for Geographic Information Science. University Technology Malaysia, Malaysia, pp: 219.

Christiansen, J.E., 1941. The uniformity of application of water by sprinkler system. J. Agric. Eng., 22: 89-92.

Gardenas, A.I., J.W. Hopmans, B.R. Hanson and E.J. Simunek, 2005. Two-dimensional modeling of nitrate leaching for various fertigation scenarios under micro-irrigation. Agric. Water Manage., 74: 219-242. DOI: 10.1016/j.agwat.2004.11.011

Isasks, E.H. and R.M. Srivastava, 1989. Applied Geostatistics. Oxford University Press, New York, Oxford. ISBN: 9780643097803.

Krige, D.G., 1984. Geostatistics and the definition of uncertainty. Inst. Min. Met. Trans., 93: A41-A47. 
Li, J. and M. Rao, 2000. Sprinkler water distributions as affected by winter wheat canopy. Irrig. Sci., 20: 29-35. DOI: 10.1007/PL00006715

Li, J., 1998. Modeling crop yield as affected by uniformity of sprinkler irrigation system. Agric. Water Manage., 38: 135-146. DOI: 10.1007/PL00006715

Li, J., B. Li and M. Rao, 2005. Spatial and temporal distributions of nitrogen and crop yield as affected by nonuniformity of sprinkler fertigation. Agric. Water Manage., 76: 160-180. DOI: 10.1016/j.agwat.2005.01.017

Mantovani, E.C., F.J. Villalobos, F. Orgaz and E. Fereres, 1995. Modelling the effects of sprinkler irrigation uniformity on crop yield. Agric. Water Manage., 27: 243-257. DOI: 10.1016/03783774(95)01159-G

Mateos, L., E.C. Mantovani and F.J. Villalobos, 1997. Cotton response to non-uniformity of conventional sprinkler irrigation. Irrig. Sci., 17: 47-52. DOI: 10.1007/s002710050021

Merkley, G.P. and A.P. Allen, 2004. Sprinkler and Trickle Irrigation Lecture Notes. BIE 5150/6110, Utah State University, Logan, Utah, pp: 39-41.
Merriam, J.L. and J. Keller, 1978. Farm irrigation system evaluation: A guide for management. Utah State University, Logan, Utah, pp: 271.

Pang, X.P., J. Letey and L. Wu, 1997. Irrigation quantity and uniformity and nitrogen application effects on crop yield and nitrogen leaching. Soil Sci. Soc. Am. J., 61: 257-261.

Seginer, I., 1983. Irrigation uniformity effect on land and water allocation. Trans. ASAE., 26: 116-122.

Thylen, L. and D.P.L. Murphy, 1996. The Control of errors in momentary yield data from Combine Harvesters. J. Agric. Eng. Res., 64: 271-278. DOI: 10.1006/jaer.1996.0068

Varlev, I., 1976. Evaluation of nonuniformity in irrigation and yield. J. Irrig. Drain. Div., ASCE., 102: 149-164.

Wright, J., F. Bergsrud, G. Rehm, C. Rosen, G. Malzer and B. Montgomery, 2002. Nitrogen Application with Irrigation Water-Chemigation. College of Agriculture, Food and Environmental Sciences, University of Minnesota. http://www.extension.umn.edu/distribution/cropsys tems/DC6118.html 